\title{
Cellulosic Water and Polyacrylamide Gels Can Delay Wilting and Extend Watering Intervals for Potted Poinsettias Displayed in Interiorscapes
}

\author{
Robert H. Stamps ${ }^{1}$ and Heidi M. Savage
}

AdDitional INDEX WORDs. Euphorbia pulcherrima, display life, indoor plant, slow-release water, evapotranspiration

Summary. Poinsettias (Euphorbia pulcherrima) are popular for their colorful bracts and long keeping quality under indoor conditions. However, along with the long display life comes the maintenance issue of labor-intensive repeated waterings. Three experiments were conducted to determine whether using cellulosic water $(\mathbf{C W})$ applied to the surface of the soilless growing medium as postproduction treatment could extend the days to wilt and intervals between waterings under simulated home/ office conditions. $\mathrm{CW}$ is a gel composed of water bound in a cellulose matrix; as the cellulose is broken down the water is released. In addition, polyacrylamide (PAM) granules, applied dry into holes in the growing medium or hydrated to the medium surface, were evaluated for the same purpose in the final experiment. In the first experiment, pots containing cultivar Advent Red were treated with 0,150 , or $300 \mathrm{~g}$ of CW gel. In the second experiment, pots with 'Prestige Early Red' plants received 0 , 125 , or $250 \mathrm{~g}$ of CW gel. Pots were weighed and monitored for wilt daily. The daysto-wilt response was positively linear with $\mathrm{CW}$ application rates. Days to wilt (time between waterings) increased by over 3 days for each $100 \mathrm{~g}$ of CW applied to the pots during both Expts. 1 and $2\left(y=20+0.031 x, r^{2}=0.54\right.$ and $\mathrm{y}=18.6+0.032 x$, $v^{2}=0.624$, respectively, where $\mathrm{y}=$ days to wilt and $\mathrm{x}=$ grams of $\left.\mathrm{CW}\right)$. In the third experiment, CW results were similar to those of the previous experiments. In addition, PAM initially also increased days to wilt compared with the control, with hydrated PAM applied at the same rate as $\mathrm{CW}$ providing the same benefits. However, PAM did not rehydrate adequately upon rewatering after the first wilt to delay the second wilt. This may have been due to fertilizer salts and to limited contact with the growing medium. Transpiration rates measured on the days before the untreated plants started wilting were not different among the treatments; therefore, the increased days to wilt provided by CW and PAM were due only to their providing additional water. Both CW and PAM gels were effective when used postproduction to supply supplemental water and lengthen the time period before the potted poinsettias wilted when held in interiorscapes.

$\mathrm{P}$ oinsettias are popular for their colorful bracts and long keeping quality under indoor conditions. However, along with the long display life comes the maintenance issue of repeated waterings that can be labor intensive. It would be useful to have a slow-release water product that could be applied postproduction when extended watering intervals are desired. CW is a soft gel formed by combining a cellulosic substrate (e.g., carboxylmethylcellulose)

\footnotetext{
University of Florida, Institute of Food and Agricultural Sciences, Environmental Horticulture Department, Mid-Florida Research and Education Center, 2725 South Binion Road, Apopka, FL 32703-8504

We thank Jesse Anderson and Annette Chandler for technical assistance; Jim Barrett and Carolyn Bartuska, Department of Environmental Horticulture, University of Florida, Gainesville, and Bill Dewar, Dewar Nurseries, Apopka, Florida, for donation of the plants; and the Florida Agricultural Experiment Station for support.
}

${ }^{1}$ Corresponding author. E-mail: rstamps@ufl.edu.

with a hydrated metallic salt (e.g., zinc sulfate) (Avera, 1989). When the gel is in contact with the growing medium, the water is slowly released as the microorganisms in the growing medium produce cellulolytic enzymes that break down the cellulose matrix (Avera, 1989; Nie et al., 2004). This slow release of the water has the potential to extend watering intervals. There are no peer-reviewed publications dealing with the use of CW for supplying water for containerized plants indoors. The only paper in the literature that evaluated $\mathrm{CW}$ for use with containerized plants used azaleas (Rhododendron indicum) held in a shaded greenhouse and $\mathrm{CW}$, applied at the recommended rate to the growing medium surface, kept the plants from wilting through the 4 -week evaluation period (Dellavalle, 1992).

Unlike PAM granules, CW comes fully hydrated as a result of the manufacturing process. With PAM, the amount of hydration can vary with water quality, growing medium, presence of fertilizer salts, and other factors (Bowman et al., 1990; Foster and Keever, 1990; Johnson, 1984; Lu et al., 2002; Shim and Choi, 2010; Woodhouse and Johnson, 1991). CW differs from PAM in that it does not have the potential to rehydrate. Another difference between CW and PAM are the recommendations on their use. $\mathrm{CW}$ is applied with limited contact with the growing medium and not mixed with it, whereas PAM is mixed thoroughly with the growing medium before planting or applied with full growing medium contact down holes made in the growing medium of pots with established plants. For CW, the contact area between the gel and the substrate, as well as the microbial populations, affect the rate of water release (Solidwater, 2011). With PAM, water release is an osmotic mechanism. The two objectives for these experiments were to see whether using CW could extend the days to wilt and intervals between waterings of potted poinsettias held under simulated home/ office conditions and to see if PAM granules applied postproduction could also extend the time to wilt under the same interiorscape conditions.

\begin{tabular}{llll}
\hline $\begin{array}{l}\text { Units } \\
\text { To convert U.S. to SI, } \\
\text { multiply by }\end{array}$ & U.S. unit & SI unit & $\begin{array}{l}\text { To convert SI to U.S., } \\
\text { multiply by }\end{array}$ \\
\hline 29.5735 & $\mathrm{fl} \mathrm{oz}$ & $\mathrm{mL}$ & 0.0338 \\
0.3048 & $\mathrm{ft}$ & $\mathrm{m}$ & 3.2808 \\
2.54 & inch $(\mathrm{es})$ & $\mathrm{cm}$ & 0.3937 \\
16.3871 & inch & $\mathrm{cm}^{3}$ & 0.0610 \\
1000 & $\mathrm{mmho} / \mathrm{cm}$ & $\mu \mathrm{S} \cdot \mathrm{cm}^{-1}$ & 0.0010 \\
28.3495 & $\mathrm{oz}$ & $\mathrm{g}$ & 0.0353 \\
1.7300 & $\mathrm{oz} / \mathrm{inch}^{3}$ & $\mathrm{~g} \cdot \mathrm{cm}^{-3}$ & 0.5780 \\
1 & $\mathrm{ppm}$ & $\mathrm{mg} \cdot \mathrm{L}^{-1}$ & 1 \\
$\left({ }^{\circ} \mathrm{F}-32\right) \div 1.8$ & ${ }^{\circ} \mathrm{F}$ & ${ }^{\circ} \mathrm{C}$ & $\left({ }^{\circ} \mathrm{C} \times 1.8\right)+32$
\end{tabular}




\section{Materials and methods}

Three experiments using potted poinsettias were conducted in $10 \times$ 10 - $\mathrm{ft}$ acclimatization rooms at the University of Florida's Mid-Florida Research and Education Center (Apopka, FL). Plants with fully colored mature bracts were used in Expts. 1 and 2. At the start of Expt. 3 the plants were at the first color stage so the bracts developed color in the interior environment.

Expт. 1. 'Advent Red' poinsettias were greenhouse grown under natural day conditions in 6.5 -inch azalea pots containing a Canadian sphagnum moss and perlite growing medium (2P; Conrad Fafard, Agawam, MA). During production, plants were fertilized with a liquid $20 \mathrm{~N}-4.4 \mathrm{P}-$ $16.6 \mathrm{~K}$ fertilizer containing micronutrients (Peters 20-10-20; Scotts, Marysville, $\mathrm{OH}$ ) that supplied $300 \mathrm{ppm}$ nitrogen. On 23 Mar. 2010, plants of uniform size were irrigated to container capacity and randomly divided into three groups for treatment applications. CW (Solidwater; Amerisupply, Sanford, FL) treatments were 0,150 , or $300 \mathrm{~g} /$ pot. With the pot on a weighing scale, the gel was squeezed out of the flexible plastic packaging by hand and, if needed, a spatula was used to spread the gel evenly over the growing medium surface. Treatment rates provided $\mathrm{CW}$ mass to volume of growing medium ratios of $0,0.086$, and $0.172 \mathrm{~g} \cdot \mathrm{cm}^{-3}$. Plants were held in a room set up to simulate a home/ office environment. Room conditions were maintained at $19.5 \pm 1.5^{\circ} \mathrm{C}$ and $65 \% \pm 9 \%$ relative humidity $(\mathrm{RH})$, with $12 \mathrm{~h}$ of light/day at $13.6 \mu \mathrm{mol} \cdot \mathrm{m}^{-2} \cdot \mathrm{s}^{-1}$ provided by daylight fluorescent lamps (F34T 12/CW/RS/EW Alto; Philips Lighting, Somerset, NJ). When a plant first reached the wilt threshold (50\% or more of the bracts and leaves wilted), it was rewatered to container capacity by slowly pouring $800 \mathrm{~mL}$ of water evenly over the growing medium surface and letting the pots stand for $30 \mathrm{~min}$ in the excess water collected in a saucer. CW treatments were reapplied and a second days-to-wilt period was determined. Expt. 1 ended on 24 May 2010.

Expт. 2. 'Prestige Early Red' poinsettias were grown in 6-inch azalea pots equipped with cage supports using the same growing medium and fertilization program as in Expt. 1.
On 15 Nov. 2010, plants of uniform size were irrigated to container capacity and randomly treated with one of three CW application rates: 0,125 , or $250 \mathrm{~g} /$ pot. CW treatments were applied evenly over the soil surface. Treatment rates provided ratios of $\mathrm{CW}$ to growing medium volume similar to those in the previous experiment: $0,0.088$, and $0.176 \mathrm{~g} \cdot \mathrm{cm}^{-3}$. Evaluation rooms were maintained at $20.5 \pm 2.5^{\circ} \mathrm{C}$ and $56 \% \pm 20 \% \mathrm{RH}$, with $12 \mathrm{~h}$ of light/day at $15.4 \mu \mathrm{mol} \cdot \mathrm{m}^{-2} \cdot \mathrm{s}^{-1}$ provided by daylight fluorescent lamps. When a plant first wilted, it was rewatered to container capacity and CW treatments were reapplied for a second days-to-wilt evaluation. Expt. 2 ended on 14 Jan. 2011.

EXPT. 3. 'Prestige Early Red' poinsettias were grown in 6-inch azalea pots using a Canadian peat:perlite (70:30) growing medium (2S; Florida Potting Soils, Orlando, FL) and top-dressed with $9 \mathrm{~g}$ of a $14 \mathrm{~N}-6.2 \mathrm{P}-$ $11.6 \mathrm{~K}$ slow-release fertilizer (14-1414; Harrells, Lakeland, FL). On l Nov. 2011, previously watered plants of uniform size were l) treated with $3.64 \mathrm{~g} /$ pot of dry PAM granules (Soil Moist; JRM Chemical, Cleveland, $\mathrm{OH}$ ) distributed down four evenly spaced 1/4-inch-diameter by 4 -inchdeep holes in the growing medium and then covered with growing medium, 2) top-dressed with $250 \mathrm{~g} / \mathrm{pot}$ of hydrated PAM, 3 ) top-dressed with $250 \mathrm{~g} /$ pot of CW, or 4) left untreated. These hydrated PAM and CW application rates were the same as the high CW application rate in Expt. 1. The hydrated PAM was prepared using tap water $\left(\mathrm{pH} 8.24\right.$, EC $\left.425 \mu \mathrm{S} \cdot \mathrm{cm}^{-1}\right)$ and after $2 \mathrm{~d}$ of soaking the water adsorption ratio was $109 \mathrm{~g}$ water per gram of PAM. Therefore, the hydrated PAM application rate was equivalent to $2.3 \mathrm{~g}$ of dry PAM per pot. All pots were rehydrated to container capacity and placed in the evaluation rooms that were maintained at $20.5 \pm 2.5^{\circ} \mathrm{C}$ and $56 \% \pm 20 \% \mathrm{RH}$, with $12 \mathrm{~h}$ of light/day at $15 \mu \mathrm{mol} \cdot \mathrm{m}^{-2} \cdot \mathrm{s}^{-1}$ provided by daylight fluorescent lamps. When a plant first wilted, it was rewatered to container capacity for a second wilt evaluation. Only the CW treatment was reapplied. Expt. 3 ended on 24 Dec. 2011.

Data collected. All pots were weighed and the plants were visually monitored for wilt at the same time on a daily basis. The threshold for rewatering was when $50 \%$ or more of the bracts and leaves were wilted. If a plant was wilted, the pot was rewatered to container capacity and reweighed. Transpiration of both leaves and bracts was measured using a steady state porometer (LI-1600; LI-COR, Lincoln, NE) with a $2-\mathrm{cm}^{2}$ broadleaf aperture. Readings were taken on the most recently fully expanded leaves and bracts at or near the top of the plant canopy.

Experimental Design. For the first two experiments, each treatment was replicated 10 times in a randomized complete block (RCB) design. There were eight replications in the RCB design in the third experiment. Statistical analysis was done using analysis of variance (ANOVA) and analysis of covariance (ANCOVA) with means separation by Duncan's new multiple range test (MRT) at $P \leq$ 0.05 [GLM (SAS version 9.2; SAS Institute, Cary, NC)]. Regression analysis was done using graphics software (SigmaPlot version 11; Systat Software, San Jose, CA).

\section{Results and discussion}

Evapotranspiration. Cumulative water loss before any plants were visibly wilted was linear $\left(r^{2}\right.$ values from 0.9999 to 0.9964 ) and greater $(P \leq 0.05$, Duncan's MRT) from the pots treated with the high rates of $\mathrm{CW}$ than the untreated controls from day 3 and day 2 onward for the days-tofirst-wilt evaluations for Expts. 1 and 2 , respectively (Fig. 1). Average pot weight losses for the $17 \mathrm{~d}$ from experiment initiation were 29 and $31.5 \mathrm{~g} \cdot \mathrm{d}^{-1}$ for the control and high CW-treated pots, respectively, for those experiments. This difference in weight loss could be due to evaporation of water from the CW on the soil surface, from higher transpiration because of greater water availability in the $\mathrm{CW}$-treated pots, or a combination of both factors. However, transpiration rates for neither bracts nor leaves were different because of treatments during these pre-wilt periods (data not shown) suggesting that the greater weight loss is from evaporation from the $\mathrm{CW}$ gel that covered almost all the growing medium surface at the high application rates. Weight loss was intermediate for the middle $\mathrm{CW}$ treatments and was likely due to the reduced exposed CW surface area at the lower application rate. Evaporation from 
the wet gel surface would be greater than that from the growing medium. In Expt. 3, there were no differences in cumulative water losses until day 11 when losses from the hydrated PAM treatments were greater than from the controls (Fig. 2) because of the wilting of the first control plant. Up to that point, there were no differences in transpiration (data not shown).

DAYs to wiLt. The results from the first two experiments were very similar despite using different cultivars and pot sizes; however, the $\mathrm{CW}$ mass to growing medium volume ratios in both experiments were similar. The time intervals until the poinsettias wilted increased linearly $(P<$ 0.001, ANOVA) with the addition of CW. Running ANCOVA confirmed that the slopes of the days-to-wilt lines for the first and second wilts in each experiment were not different. The second applications of $\mathrm{CW}$ were as effective as the initial applications; therefore, the combined regressions are reported (Fig. 3). The slopes were slightly greater than 0.03 indicating an increase in days to wilt of $\approx 3 \mathrm{~d}$ for every $100 \mathrm{~g}$ of $\mathrm{CW}$ added to the pots. In Expts. 1 and 2, application of CW at the high rates increased days to wilt by over 1 week and extended the interval until plants wilted to 4 weeks. These results are consistent with a previous greenhouse study (Dellavalle, 1992). Applying CW a second time doubled the cumulative days to wilt. Since the CW treatments did not affect transpiration, these increases in days to wilt were due solely to the additional water provided by the CW. The time of wilt for the CW-treated pots coincided with the disappearance of gel on the growing medium surface; in Expt. 3 that was the case for both CW and hydrated PAM. CW and PAM treatments increased days to first wilt compared with the control by $3.25 \mathrm{~d}$ (dry PAM) to $5.5 \mathrm{~d}(\mathrm{CW})$ with the increase from $\mathrm{CW}$ greater than dry PAM (Fig. 4). Days to second wilt were greater $(7.9 \mathrm{~d}, 41 \%)$ for $\mathrm{CW}$-treated plants than control plants. This is similar to the results of the first two experiments since $95 \mathrm{~g}$ of $\mathrm{CW}$ provided an average increase before the plants wilted of $3 \mathrm{~d}$. Again, this increase was due to the additional water from the $\mathrm{CW}$ and not to any effect of the CW treatments on transpiration. However, for the second

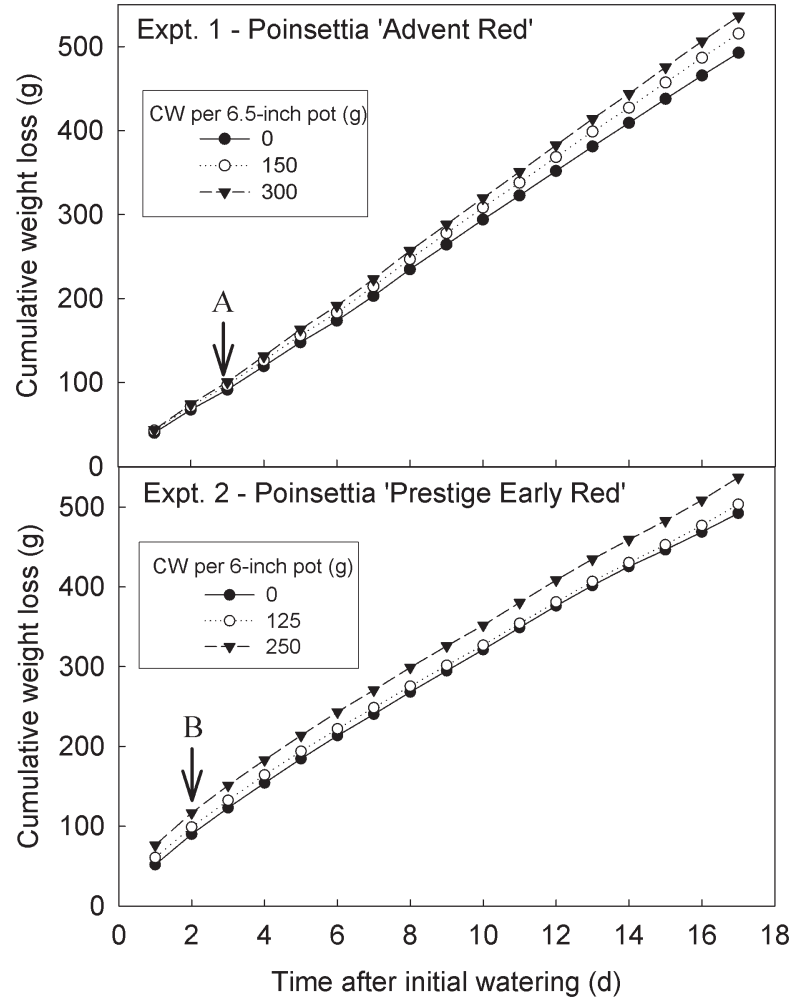

Fig. 1. Pots of finished poinsettias were top-dressed with cellulosic water $(\mathrm{CW})$ gel and held under simulated home/office conditions. Pots were weighed daily. Each symbol represents the mean of 10 plants. Cumulative weight losses at the high $\mathrm{CW}$ application rates were higher than the untreated pots starting at (A) $3 \mathrm{~d}$ or (B) $2 \mathrm{~d}$ after experiment initiation (Duncan's multiple range test at $P \leq 0.05$ ). In Expt. 1, cumulative water losses were intermediate for the middle CW application rate. In Expt. 2, water losses from the intermediate rate were not different from the control, but were less than those from the high CW rate treatment; $1 \mathrm{~g}=0.0353 \mathrm{oz}, 1$ inch $=2.54 \mathrm{~cm}$.

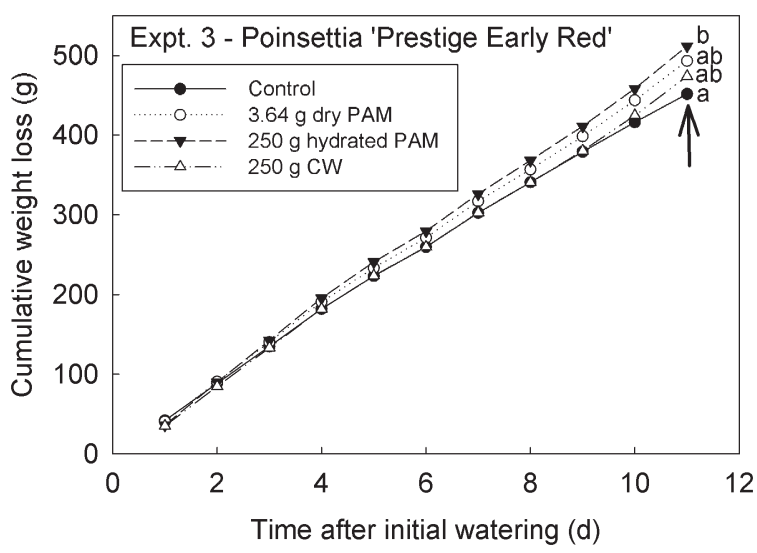

Fig. 2. Finished poinsettias in 6.5 -inch $(16.51 \mathrm{~cm})$ pots were treated with dry polyacrylimide (PAM) gel placed into holes bored in the growing medium, top-dressed with hydrated PAM, top-dressed with cellulosic water $(\mathrm{CW})$ gel, or left untreated. Pots were held under simulated home/office conditions and pots were weighed daily. Each symbol represents the mean of eight plants. Cumulative weight losses were not different until day 11 (Duncan's multiple range test at $P \leq 0.05$ ); $1 \mathrm{~g}=0.0353 \mathrm{oz}$.

wilt in Expt. 3, the PAM-treated plants did not last longer than the control plants and there was no visible evidence of rehydration of the PAM on the growing medium surface following the watering after the first wilt. This lack of PAM rehydration may have been due to fertilizer salts (Bowman 

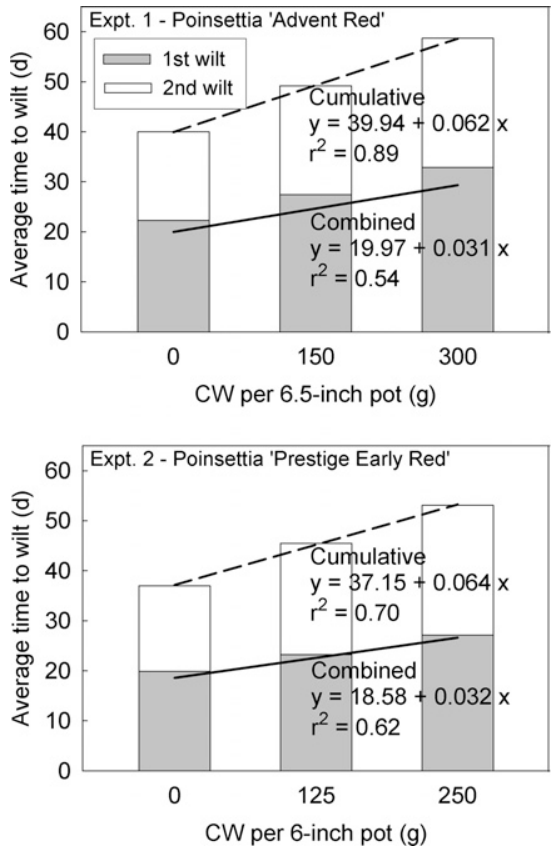

Fig. 3. Pots of finished poinsettias were top-dressed with cellulosic water $(\mathrm{CW})$ gel and held under simulated home/ office conditions. Plants were monitored daily for wilt. The threshold for rewatering was $50 \%$ or more of the bracts and leaves wilted. Treatments were replicated 10 times; $1 \mathrm{~g}=\mathbf{0 . 0 3 5 3} \mathrm{oz}$, 1 inch $=2.54 \mathrm{~cm}$.

et al., 1990; Johnson, 1984; Wang and Gregg, 1990), especially near the soil surface where the controlled-release fertilizer had been top-dressed during production, and to limited contact between the PAM and growing medium. As mentioned previously, PAM granules were not visible at the end of the first wilt. These factors may be part of the reason that users of PAM are instructed to mix the PAM with the growing medium.

In greenhouse experiments, the water-holding capacity of PAM hydrogels declined over time (Al-Harbi et al., 1999; Frantz et al., 2005; Wang and Gregg, 1990); however, the decline was not so pronounced as in this interiorscape study. Further evidence of this lack of rehydration is that the weights of the dry and hydrated PAMtreated pots were $11 \%$ and $19 \%$ less, respectively, after the second watering than after the first and only $5 \%$ and $4 \%$ heavier, respectively, than the untreated controls. The reduction in pot weights for the hydrated PAM treatment was equal to $\approx 85 \%$ of the water weight when it was first applied.

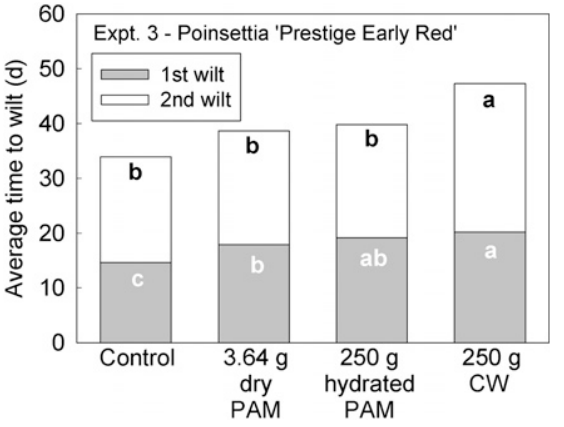

Fig. 4. Finished poinsettias in 6.5-inch $(16.51 \mathrm{~cm})$ pots were treated with dry polyacrylimide (PAM) gel placed into holes bored in the growing medium, top-dressed with hydrated PAM, topdressed with cellulosic water (CW) gel, or left untreated. Treatments were replicated eight times. Pots were held under simulated home/office conditions and plants were monitored daily for wilt. The threshold for rewatering was $50 \%$ or more of the bracts and leaves wilted. Different letters for each wilt (first and second) are significantly different by Duncan's multiple range test at $P \leq 0.05 ; 1 \mathrm{~g}=$ $0.0353 \mathrm{oz}$.

The somewhat lower reductions in weights after rewatering of the dry PAM-treated pots compared with the top-dressed PAM could be due to lower fertilizer concentrations away from the medium surface and greater area of physical contact with the growing medium from which water could be absorbed during rewatering. In addition, less PAM was applied in the hydrated treatments than in the dry PAM applications ( 2.3 vs. $3.64 \mathrm{~g} / \mathrm{pot}$ ). The PAM results are in contrast to the control and $\mathrm{CW}$-treated pots that weighed within $2 \%$ to $3 \%$ of their initial weights after the second rehydration.

\section{Conclusions}

CW was effective as a postproduction treatment in supplying water for at least 4 weeks and delayed wilt of containerized poinsettias held under simulated home/office conditions. This delaying of wilting was not due to any decrease in transpiration and was due to the additional water supplied by the CW. Inclusion of an evaporation barrier over the $\mathrm{CW}$, as well as the hydrated PAM, might increase their efficacy slightly. Under the conditions of Expt. 3, top-dressed hydrated PAM was equally effective in supplying water but was not capable of rehydration after drying out. Although the dry PAM was applied according to the manufacturer's directions and at a rate $58 \%$ greater than that of the hydrated PAM treatment, it was not able to fully hydrate with a single watering.

These slow-release water sources could be used by interiorscapers to prolong the time before plants need to be rewatered, thereby reducing labor. Consumers could also use these products to maintain plants indoors while away from home. CW might also have application at the retail level in situations where the water demands of the plants were not too great. Additional research is needed to determine application and use strategies for $\mathrm{CW}$ with other crops and environmental conditions.

\section{Literature cited}

Al-Harbi, A.R., A.M. Al-Omran, A.A. Shalaby, and M.I. Choudhary. 1999. Efficacy of a hydrophilic polymer declines with time in greenhouse experiments. HortScience 34:223-224

Avera, F.L. 1989. Moisturizing agent. U.S. Patent $4,865,640$. U.S. Patent and Trademark Office, Washington, DC.

Bowman, D.C., R.Y. Evans, and J.L. Paul. 1990. Fertilizer salts reduce hydration of polyacrylamide gels and affect physical properties of gel-amended container media. J. Amer. Soc. Hort. Sci. 115:382386.

Dellavalle, N.B. 1992. Efficacy test of driwater - A slow water release substrate. Commun. Soil Sci. Plant Anal. 23:25472553.

Foster, W.J. and G.J. Keever. 1990. Water absorption of hydrophilic polymers (hydrogels) reduced by media amendments. J. Environ. Hort. 8:113-114.

Frantz, J.M., J.C. Locke, D.S. Pitchay, and C.R. Krause. 2005. Actual performance versus theoretical advantages of polyacrylamide hydrogel throughout bedding plant production. HortScience 40:2040-2046.

Johnson, M.S. 1984. Effect of soluble salts on water-absorption by gel-forming soil conditioners. J. Sci. Food Agr. 35:1063-1066.

Lu, J.H., L. Wu, and J. Letey. 2002. Effects of soil and water properties on anionic polyacrylamide sorption. Soil Sci. Soc. Amer. J. 66:578-584. 


\section{Research Reports}

Nie, H.R., M.Z. Liu, and Z.B. Chen. 2004. Kinetic study on bio-degradation of carboxymethylcellulose hydrogel. Acta Physico-Chimica Sinica 20:386-390.

Shim, M.S. and S.Y. Choi. 2010. Growth of Ardisia pusilla as affected by starch or polyacrylate polymer mixed in the media. Hort. Environ. Biotechnol. 51:239-244.
Solidwater. 2011. The how it works! 11 Sept. 2012. <http://www.solidwater.us/ 4.html>.

Wang, Y.T. and L.L. Gregg. 1990. Hydrophilic polymers-their response to soil amendments and effect on properties of a soilless potting mix. J. Amer. Soc. Hort. Sci. 115:943-948.
Woodhouse, J. and M. Johnson. 1991. Effects of soluble salts and fertilizers on water storage by gelforming soil conditioners. Acta Hort. 261-269. 